\title{
Educational change in Scotland: Policy, context and biography
}

Mark Priestley (University of Stirling) and Kate Miller (University of the West of Scotland)

Corresponding author:

Dr Mark Priestley

School of Education

University of Stirling

Stirling

FK9 4LA

Scotland

Email: m.r.priestley@stir.ac.uk

\section{Abstract}

The poor success rate of policy for curriculum change has been widely noted in the educational change literature. Part of the problem lies in the complexity of schools, as policymakers have proven unable to micromanage the multifarious range of factors that impact upon the implementation of policy. This paper draws upon empirical data from a local authority-led initiative to implement Scotland's new national curriculum. It offers a set of conceptual tools derived from critical realism (particularly the work of Margaret Archer), which offer significant potential in allowing us to develop greater understanding of the complexities of educational change. Archer's social theory developed as a means of explaining change and continuity in social settings. As schools and other educational institutions are complex social organisations, critical realism offers us epistemological tools for tracking the ebbs and flows of change cycles over time, presenting the means for mapping the multifarious networks and assemblages that form their basis.

Keywords: curriculum; change; socio-cultural 


\section{Educational Change in Scotland: Policy, Context and Biography}

\section{Introduction}

As has been widely noted in the research literature (e.g. Sarason 1990; Cuban 1998; Elmore 2004), educational change is highly problematic. As schools engage with new policy, there typically exists an implementation gap (Supowitz and Weinbaum, 2008) as social practices fail to match policy rhetoric. This central problem of educational change - the ubiquity of educational innovation (initiatives to bring about change) and the correspondingly weak rate of return in terms of actual changes in the social practices that comprise teaching and learning in schools - raises important questions. For example, why is externally initiated innovation so often unsuccessful in changing schools? What are the barriers that inhibit the successful take up of such innovation in schools? What factors might promote sustainable changes to the practices of schooling? And how do we come to understand the complex array of factors that impact on the enactment of new policy in schools?

According to Hayward and Spencer (2010, 175), writing about the implementation of assessment policy in Scotland, there is an urgent 'need to understand more deeply the nature of [such] complexity and to find ways of responding to it.' This paper offers an approach which seeks to develop such understanding. We utilise a particular socio-cultural theory, derived from critical realism (Archer 1995; Elder-Vass 2008a) to examine how social activity is dependent upon an assemblage of different factors, including material contexts, departmental and school culture and human biography. The research is fundamentally an analysis of the activity occurring in schools and other implementation spaces in response to the espousal of new government policies and the promulgation of programmes by local education authorities that are designed to promote the policies in question. In the light of such conditions, we acknowledge the importance of attending to the transactions between different actors, and between actors and their contexts. We recognise the inevitability of teacher mediation of policy (Osborn et al. 1997) - 
the iterative refraction (Supovitz 2008) that occurs as policy is translated as it migrates from setting to setting - as well as the corollary that traditional methods of curriculum evaluation, based upon notions of fidelity of implementation, should be treated with caution (Cuban 1998).

In conducting such analysis, the paper reports upon a particular initiative designed to bring about and sustain change. The context is provided by a set of policies initiated by a Scottish Education Authority, The Highland Council, to promote the development of formative assessment practices (especially peer and self assessment) and to facilitate the introduction of a new national curriculum development, Scotland's Curriculum for Excellence (CfE). The paper draws upon a number of case studies - teachers taking part in a Highland Council development project - and empirical data generated from teacher network meetings and focus group sessions connected to the project.

The paper first describes the research setting, before outlining some of the key tenets of critical realist theory. We then provide an overview of some key findings, before concluding by illustrating how this theory might facilitate and illuminate the analysis of data.

\section{Innovation and change in The Highland Council}

Since 2002, schools in Scotland have been faced with a series of curricular and pedagogical innovations that arguably present new and radical visions of schooling. The new Curriculum for Excellence has been heralded by its architects as 'one of the most ambitious programmes of educational change ever undertaken in Scotland' (Scottish Government 2008, 8). It is said to build upon earlier programmes of reform, notably Assessment is for Learning (AifL: see, for example, Hayward et al. 2004; Hutchinson and Hayward,2005), which have sought to shift the emphasis in classrooms away from inputs by teachers towards the development of autonomous, self-directed learners. In common with AifL, the new curriculum is claimed to be distinctive in that it explicitly moves away from central prescription of curriculum, towards a model that relies upon the professional capacity of teachers to adapt curriculum guidance to meet the needs of local school communities. The Highland Council has, 
since 2002, developed a distinctive model for the enactment of these national policies. Highland policy includes the following initiatives:

- An ongoing programme of teacher professional learning (TPL) since 2003 to foster the development of formative assessment. This has involved substantial input from academics and other external trainers, addressing, for example, work on the management of change, and the development of thinking skills. In developing such a model, Highland explicitly moves away from the 'tips for teachers' approach inherent in their earlier teacher development programmes. These programmes tended to focus on the development of pedagogic techniques (for example, traffic lighting, questioning techniques and feedback through marking), rather than being concerned with broader purposes of education. The subsequent development of a coordinated model and a set of underpinning principles participation, dialogue, engagement and learning (see figure one below) has formed the basis of the Highland approach to TPL. The Highland model is explicitly underpinned by an assumption that learning episodes should epitomise these principles, leading ultimately to the development of the capacity for critical and creative thinking, and for metacognition. Instead of teachers being told to adopt certain techniques such as those listed above (with the attendant risks that these will be adopted uncritically), such techniques were to be seen as tools that were expressly fit for purpose to achieve specific educational goals.

Figure one: the Highland Model

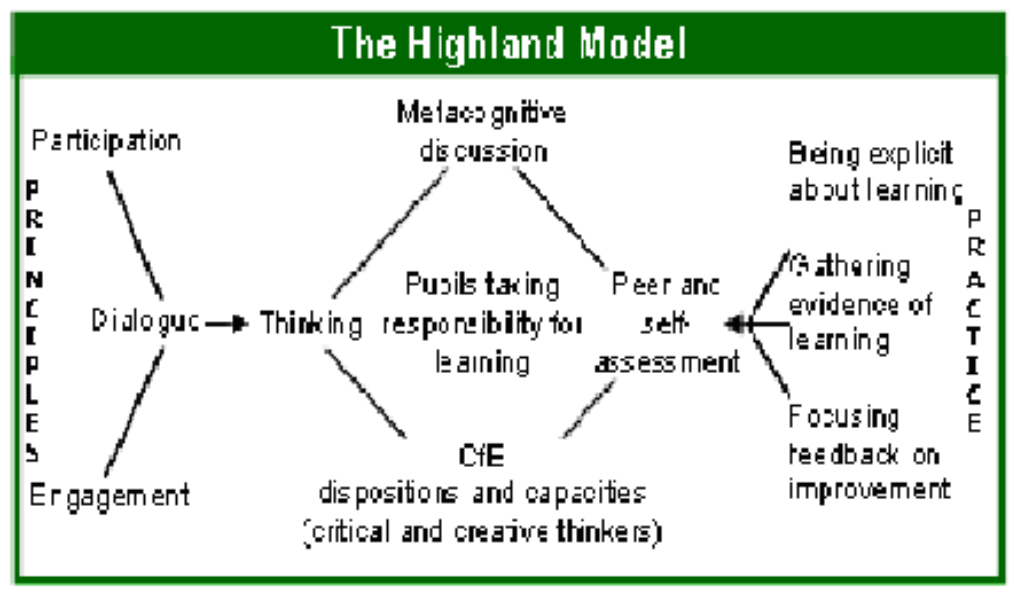


- In parallel to this programme of TPL and the development of the model, a Future Learning and Teaching (FLaT) project ${ }^{1}$ was established in 2006. This brought together several clusters of schools to explore ways of developing formative assessment (especially peer and self assessment), guided by the Highland model (see Hayward and Boyd 2009 for an evaluation of this project).

- Further to the work conducted within the FLaT project, five Associated Schools Groups (ASGs) - subject specific teacher networks - were established in 2006-7, bringing together secondary school teachers in the following subjects: English; Mathematics; Modern Foreign Languages; Science; and the Social Subjects (Geography, History, Modern Studies). Each group was coordinated by a subject leader, a practising teacher in the subject in question. These groups produced case studies detailing innovation in formative assessment. During 2007-8, they were to provide the context for our research. At this latter stage, each group was supported by a university researcher, and guided by a clear, but openended remit to develop peer and self assessment strategies for the classroom, through the medium of action research projects.

\section{Critical realism}

Critical realism has not been widely used in the field of education, with some notable recent examples (Scott 2000, 2010; Wheelahan 2010). Nevertheless, it articulates several concepts which have great relevance when investigating the social practices involved in educational change. We provide here a short overview of some of the key ideas. First, critical realism posits the concept of stratification of society, with successive layers emerging from those below. Thus, for example, a school is stratified, comprising individuals, social groupings (such as departments) and the school as a whole. In turn, the school may be seen as a sub-stratum of the wider educational system, and in turn the whole of society. Key to this depth ontology is the concept of emergence. Each successive stratum possesses properties not possessed by the individual entities that come together to form the emergent whole. Thus, for example, a social group such as a school department will possess certain 
emergent properties (for example certain forms of power/social influence) not possessed by the individuals within the group, by dint of the relationships that bind it together (see Elder-Vass 2007, 2008b for a fuller discussion of these issues).

A second key tenet of critical realism is that social entities and their properties exist independently of our knowledge of them. For instance, social structures, customs and traditions, are real in that they persist in time and space, existing independently of and anterior to the knower, and exerting causative influences on social events and the actions of people (Archer 1995). Conversely, social relations act to change or preserve existing social objects, as well as leading to the evolution or emergence of new cultural, structural and individual forms (Archer 1995; Elder-Vass 2008a, 2008b).

Figure two: social reproduction and transformation

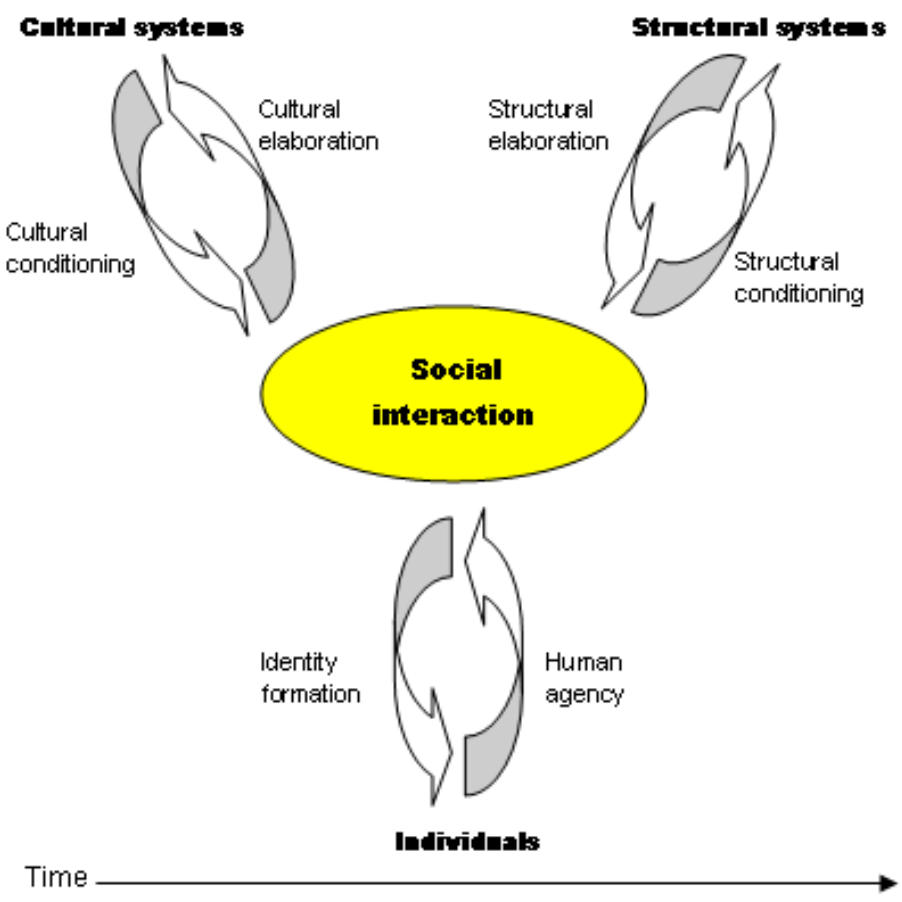

A third dimension is provided by Archer's (1988) notion of analytical dualism. This was formulated to enable separation of the individual from society when undertaking social analysis. For the purpose of this paper we have utilised this 
notion of analytical separation to differentiate between culture, structure and individuals. The diagram above (figure two), derived from Archer's (1988, 1995) social theory, illustrates how a social system might be represented in this way. It shows how cultural/structural systems and human agency are prior to and exert causative influences on human interactions, and how such interactions subsequently lead to the emergence of new (or renewed) structural, cultural and individual forms. This is a temporal process.

Analytical dualism, in contrast with Giddens's (1984) theory of structuration allows us to disentangle the various aspects that contribute to the unfolding of a given social situation, enabling us to make judgments about the relative causative weight of culture, structure and agency in any given social situation. Archer (1988) suggests that in structuration theory there is no easily discernible distinction between conditions and actions. She asserts that the duality of structure and agency in structuration theory 'effectively precludes a specification of when there will be more voluntarism and more determinism' (Archer, 1988, p. 86). Archer believes that social acts are not equally fettered by the system and, in turn, that they do not each have the same degree of effect on the cultural and structural systems. Although she cautions that it is not always possible to specify the causal mechanisms that lead to variations in agency, particularly in complex social organisations such as schools, she suggests that analytical dualism allows us to at least attempt such analysis. Archer suggests that transactions between culture, structure and the individual occur at what she calls the socio-cultural level. It is useful at this point to say a little more about each of these three aspects of social reality.

According to Archer (1988), the cultural system is made up of cultural forms. Archer uses the term culture to describe beliefs, values, norms, ideas and other kinds of information, rather than in a narrow 'this is the way we do things' sense. Archer (p. 154) suggests that 'contradictions [in the cultural system] are 'site[s] of cultural tension', which constitute problem-ridden situations for human actors, leading to social elaboration.

Another aspect of social reality is the structural system. Social structures have been defined variously, by different thinkers. Critical realism differs from the 
somewhat deterministic view of social structures as collective rules and resources that govern human behaviour (Giddens 1984; Porpora 1998), but even here there is disagreement amongst different advocates of critical realism. Porpora (1998, 339) defines them rather narrowly as the emergent properties of 'systems of human relationships among social positions'. In contrast, Elder-Vass (2008b) suggests that social structures comprise the constituent parts, the relations between them, the emergent whole and the emergent properties of the whole. Nevertheless, despite these definitional differences, critical realists would agree that:

the causal effects of structure on individuals are manifested in certain structured interests, resources, powers, constraints and predicaments that are built into each position by the web of relationships (Porpora 1998, 344).

Such emergent properties, in combination with cultural forms, provide the material conditions within which human activity occurs, although they do not necessarily determine such activity, given that humans are creative, reflexive and reflective, and have the capacity to act counter to such constraints. Cultural and structural systems pre-exist human activity. As well as providing the context for human activity, they are modified by the intended and unintended consequences of such activity (Archer 1995). Seen in this way, human agency is in part an effect of the interplay of the cultural and structural systems - something to be achieved, the extent of which will vary for individual actors from one social setting to the next. However, agency is also subject to human reflexivity and is a cause of further social elaboration. This is a temporal process of successive morphogenetic (change) and morphostatic (continuity) cycles as new cultural, structural and individual properties emerge, and as existing patterns are perpetuated.

Archer (1988) suggests that, while we may separate the cultural and structural systems for analytical purposes, they are intertwined. Culture and structure are parallel but autonomous systems, interplay between them occurring through socio-cultural interaction. Particular cultural forms and social structures may operate in symbiosis. For example, ideologies relating to 
accountability in school (cultural forms) enable the persistence of power that is an emergent property of certain roles and systems in schools (social structures), and in turn such roles serve to perpetuate and develop the ideology in question. In combination, the existence of the ideology and the roles and systems help shape different forms of teacher agency, and influence how certain teachers are able to bring to bear particular experiences and values in acting within these constraints.

Critical realism, particularly Archer's social theory, provides many possibilities for theorising curriculum change. The key concepts are stratification, analytical dualism, emergence and social interaction. The depth ontology allows us theorise the existence of underlying causative mechanisms, to look beyond the obvious and the epiphenomenal. Added to this, analytical separation allows us to weigh up the relative causative weight of culture, structure and individual action in any given social interaction ${ }^{2}$. Emergence may be analysed in terms of:

- Individual emergence, for example enhanced capacity of teachers to teach.

- Structural emergence, for example the designation of new roles and systems in schools to facilitate the new policy.

- Cultural emergence, for example the refinement of the policy itself as a result of professional engagement.

The result of such emergence will be the elaboration of the social practices that are the concern of the policy. The medium for engagement, and for subsequent emergence is social interaction. The resulting practices may, or may not represent transformation, as morphostasis may result from such interaction.

Drawing upon critical realism in this way has various implications. It enables a clear distinction between innovation (i.e. multifarious policy for change) and change itself (i.e. the transformation of social practices that might result from engagement with the policy). One might then usefully characterise externally 
initiated policy prescription as cultural forms, as they represent sets of ideas about practice, with (potentially) the following features:

- They may be internally coherent or incoherent (see Priestley and Humes 2010 for an analysis of the internal coherence of CfE).

- They may be in tension with other policies creating problems for practitioners seeking to enact them (see Reeves 2008 for an analysis of how CfE is in tension with other concurrent government policies).

- They may be compatible or incompatible with existing practices and beliefs in schools.

- Practitioners charged with enacting the new policy may or may not lack the capacity to make sense of the policy intentions.

Viewing a policy as a new set of cultural forms, migrating into a social setting where they will be subject to social interaction and the causal influences of existing social structures, cultural forms and individual capacities, further allows more detailed analysis. According to Archer (1988), there are three archetypal emergent outcomes of such a process:

1. the new idea supplants the old (morphogenesis);

2. the old ideas are maintained and the new rejected (morphostasis);

3. or, more common, elements of the new merge with elements of the old, leading to a form of morphogenesis (particularly when there are points of consensus as well as contradiction between the old and the new, or where the dissonance between them is not significant enough to merit conflict).

In summary, Archer's social theory developed as a means of explaining change and continuity in social settings. As schools and other educational institutions are complex social organisations, critical realism offers us epistemological tools for tracking the ebbs and flows of morphogenetic cycles over time, presenting the means for mapping the multifarious networks and assemblages that form the basis of events and entities. Critical realism's depth ontology allows us to infer the existence and nature of the mechanisms that underpin such events and entities. 


\section{Research design}

The data to which we applied the above theoretical insights formed part of a wider research and development project working with teachers in The Highland Council. In undertaking this research we posed the following research questions:

1. How does the project facilitate and sustain curriculum change?

2. What are the relationships between teachers' identities, beliefs, and philosophies and the ways they enact curriculum change?

3. What changes in pedagogy and provision have emerged from the project?

4. What factors may be important in sustaining change?

\section{Data}

Data were generated from three sources:

- Field notes from meetings of the five ASGs.

- Detailed notes of the proceedings of two focus group meetings representing volunteer teachers from the five ASGs.

The primary data source was five detailed case studies, which were developed from a pool of volunteer teachers (one for each ASG). Data comprised transcripts from semi-structured interviews, notes from observations of teaching and documentation provided by the participating teachers. The participants in the study were purposefully selected to represent: (a) each of the five subject-based groups; (b) teachers who enthusiastically embraced AifL tenets; (c) a variety of levels of teaching experience; and (d) both genders. Thus, we sought to get variety in the case study participants on all dimensions except one, attitudes toward AifL. The purpose of this was to examine the inter-relationship between structure, culture and individual factors when participants had in common a stated intention to enact classroom curriculum innovation. For the purposes of this particular paper, the main focus is on the third set of data, the teacher case 
studies. The research adhered to the ethical guidelines of the British Educational Research Association. While the collaborative partnership with The Highland Council is a matter for public record, the researchers were concerned to protect individual participants, for whom making statements about the enactment of council policy might entail some personal risk. While it was not possible to guarantee totally anonymity, given the personal nature of data, we sought to preserve anonymity where possible. Thus, all references to participating teachers use pseudonyms where applicable, and all data were treated as confidential by researchers working on the research project. Where the publication of data was judged to pose a risk to participants, it was reported generically.

The backgrounds and prior dispositions of the teachers are significant in shaping their responses to curriculum innovation, therefore a short biography of each is presented below.

\section{Participants}

Helen is a teacher of English, with an additional management remit in pupil guidance. She teaches at a small school, drawing from both suburban and rural neighbourhoods. Prior to teaching she worked in tourism and retail management. She enjoyed building long-standing, rather than superficial, relationships with people, and this was reflected in her approach to teaching and moreover had prompted her involvement in the Highland Council/University of Stirling research and development project

Drew is one of only two mathematics teacher at a small school, serving a geographically isolated town. At the time of the research, he was working towards a Master's qualification, linked to Chartered Teacher status ${ }^{3}$; his interest in formative assessment lay in the use of learning logs. Drew's motivation for being involved in the project stemmed from his desire to transform his own practice, as well as that of his colleagues, which he described as traditional, content-driven mathematics teaching. This teacher has an eclectic personal background and trajectory into teaching, having 
come to teaching relatively late in life after a varied biography of engineering graduate, hippy, bus driver, parent and boat builder.

Sophie teaches in a small/medium sized school which serves a small town in a rural part of Scotland. Prior to participating in this project, she had taught modern languages for seven years and, like Drew, was working on her Master's degree at the time of the study. She taught both French and German. She considered that her role was not just to teach students a language, but rather to develop them to their full potential as individuals in a holistic sense. A good deal of her teaching was dialogical, with an emphasis on developing self-assessment skills and metacognition in her students.

Vanessa is a science teacher, qualified to teach biology, chemistry, and physics. At the time of the study, she taught chemistry and biology at a rural secondary school. She had 15 years of teaching experience, including 12 years at an urban school in England, prior to moving to Scotland, and had already attained Chartered Teacher status. She was the only one of the case study teachers who chose CfE innovation, numeracy across the curriculum, as the topic for her action research project, rather than AifL innovation, for example the self and peer assessment approaches that were the focus for other participants.

Fiona, the social subjects teacher, was the least experienced practitioner amongst the participants, having only three years of teaching experience at the time of the study. This lack of experience was counter-balanced by her enthusiasm for the project, for collaborative working and by her openness to change in her own practice. Her main teaching subject was modern studies, although she also taught geography and history to junior classes in her school, which was a large secondary (by Highland standards). Fiona's unhappy experience of her own secondary schooling, throughout which she did not feel supported by her teachers, was significant in influencing her approaches to her teaching. 


\section{Data analysis}

Initial analysis consisted of interpretive coding of the interview data. Data were initially subjected to open coding, generating descriptive codes to help the researchers identify general areas of interest in relation to the research questions such as teachers' beliefs about pupils, the work of the ASGs, or their own action research projects. In the case of the volunteer teachers, this enabled us to construct five detailed case studies, which extrapolated key themes from the coding. Each provided a biographical description of each teacher and addressed the research questions explicitly. The case studies were subsequently subjected to a cross case analysis, to identify complementary and contradictory themes in the data. Finally, we applied the heuristic provided by the triad of culture, structure and the individual, derived from Archer's (1988) social theory. This analytical separation of the data enabled us to make judgements about the relative weight of culture, structure and individual factors within each of the social settings represented by the case studies

\section{Findings}

We present the findings in this final section of the paper using three headings: The policy; The context; and Biography. These sub-titles correspond to some extent with the three elements of the triad, albeit with a great deal of overlap, and have emerged from the analysis described above. In attempting an analytical separation of the data, we were especially concerned with:

- the role of the policy, as a set of new cultural forms, in influencing practice;

- how underlying social mechanisms and individual properties might impact upon the form that change in practice took;

- $\quad$ and the nature of emerging practice.

For each subsection, we draw upon examples from the empirical data, and utilise key features of the theory to make sense of the findings and to make inferences about successful curriculum change. Our focus in this paper is not 
to provide a full analysis of the project data. This is provided elsewhere (Priestley et al. 2011; Wallace and Priestley in press). Instead our intention is to illustrate how such theory may be utilised to make sense of data in respect of curriculum change.

\section{The policy}

Analysis of the policy must address two aspects. The first of these is the form that policy itself takes. This comprises the official national policy texts representing both AifL and CfE, but also the forms through which these key policies have been mediated by the Highland Council. In particular, the four Highland principles - participation, dialogue, engagement and learning - are significant. The second aspect of the policy concerns the spaces and systems that were created by the council for the purpose of facilitating engagement with policy. Although these clearly make up part of the context within which policy is enacted, they also link explicitly to the cultural forms that comprise AifL, CfE and the Highland model, each supporting the other symbiotically, as described in a previous section of the paper. In combination with these cultural forms, the social structures formed by the teacher networks and various professional learning events provided a powerful fillip to teachers who were already interested in changing their practice.

Policy provided legitimation for teacher action. All of the teachers in our case studies commented favourably on what they saw as official permission to develop ideas that were already congruent with their values. Highland Council's explicit support for co-construction of curriculum by teachers was welcomed, as was its establishment of distributed leadership of the teacher networks, by practising teachers rather than the Council's own administrators. This made it possible for relatively inexperienced teachers to take leadership roles and contribute substantively to the development of the policies in schools. These shifts in the power structures of the system seem to have opened up the potential for genuine changes in practice.

The ASGs were also identified as being useful in providing a space for reflection on practice, action research and sense making. Rebecca described 
how the project has required her to think about how the ideas expressed in CfE documentation, such as giving pupils responsibility for their own learning, actually translate into the classroom, and she hoped that her work enhanced the pupils' experience. This teacher also found the project useful for providing a space to look at a range of research and reflect on it in relation to her own pupils. Such research was provided in some cases via the university academics who supported the teacher networks, and in others via council publications.

In summary, the cultural forms and associated social structures represented by the policies provided powerful support for teachers who were already interested in developing their practice in congruent directions - through official legitimation for action, through the designation of official spaces where such action could occur, and through the provision of cultural/cognitive resources to support engagement with the policies

\section{The context}

It is clear that, in the case studies at least, the values inherent in the various policies promoted by Highland Council were largely congruent with the values of the teachers. According to the Doyle and Ponder (1977) Practicality Ethic, this is just one factor in three that impacts on how a teacher may engage with a new policy. The others are instrumentality (i.e. how easy it is to operationalise the policy) and risk (i.e. an analysis of cost/benefit). We have already noted the official legitimation of action provided by the Highland model, which went some way towards mitigating perceptions of risk in a system characterised by a strong attainment agenda (Miller et al. 2010). We have also highlighted already the role of the teacher networks - described by one teacher as a community for taking forward change - in providing a space for meeting new colleagues, sharing ideas, generating ideas through discussion and making and sustaining connections. In this section of the paper we wish to briefly focus on two of the case studies - one in which the context was propitious to practitioner engagement with the Highland model, and another in which the context militated against change. 
In the case of Rebecca, she believed that her involvement in the network had enhanced her identity within the school; she was subsequently seen as someone who gets involved, to whom colleagues come for advice. Moreover she received explicit support for her work from her head teacher, who allowed her out of school for network and other meetings, and who regarded her involvement in the Highland model as beneficial for the school. This also linked into her involvement with the school's learning and teaching committee, which made Rebecca conscious that her project was not only personal to her, but should be disseminated widely across the school. The result of this was the substantial penetration of the ideas underpinning the Highland model into her school.

This positive case compares starkly with that of Drew, who faced more challenging conditions in implementing the model into his own school. Drew worked in a small maths department in a secondary school in a small isolated town. Examination results were good, and teaching was seen by Drew as traditional and formulaic, being driven primarily by an attainment agenda. Drew believed that he was swimming against the tide in his department, which he described as being 'stuck' and very resistant to change. He clearly identified the need to change the way curriculum is enacted in the classroom, and felt strongly that this would only be possible with a greater degree of support within his department and school. As this was clearly not forthcoming, the penetration of the ideas underpinning the Highland model was limited in this school, being confined to limited changes in pedagogy in Drew's classroom.

The cultures and structures within the different departments and schools were cited as being important by a number of the case study teachers, both as enabling change through their collaborative approaches or hindering change through becoming 'stuck' in particular ways of doing things. The teacher networks mitigated this latter issue to some extent, through providing the means for teachers to meet with other like minded colleagues, and to develop new ideas and practices collaboratively. However, our research also points to the importance of attending to the contexts within which change is to occur. 
The research suggests three aspects to this: the shared beliefs and cultural traditions of teachers in the schools; the endorsement of reform by school leaders; and the existence of systems for operationalising reform (for example cross school committees which encourage horizontal and vertical professional relationships).

\section{Biography}

This final section of the paper focuses on the importance of what individuals bring to the enactment of reform. According to Spillane (1999) there are two dimensions of this: capacity (for example skills and knowledge) and will (for example beliefs about teaching and values). Our research has highlighted examples of both dimensions. The brief illustrations below show how these dimensions (in this case, primarily relating to beliefs) impact upon enactment of change.

In the case of Fiona's, the data suggest that prior beliefs and values played an important role in the ways in she engaged with initiatives such as CfE. Her interviews reveal a teacher with strong beliefs about learning, rooted in her own experiences as a learner and in the interests that she has in her subject. She was clear and explicit that she saw the job of schooling and her subject as being about enabling young people to develop into effective citizens, and this translated clearly onto methodologies that are fairly participative and which serve to develop the capacity for autonomous action. Her emphasis on the relational aspect of development (whether within the classroom or within teacher CPD) reveal a strong belief in the value of co-constructivist methods for learning. Consequently, this teacher seems to have been especially receptive to initiatives premised on such methods, despite the strong socialisation exerted by the culture of secondary teaching. It is apparent that Fiona engaged in a process of adaptation in taking forward the ideas of others' and in doing so her belief and skills have changed, although her core values about learners (a major driver for her involvement) appear to remain unchanged, even reinforced. 
Conversely, Vanessa's beliefs demonstrated how changes in practice might be inhibited by strong beliefs. In Vanessa's case, we saw strong articulated beliefs about empowering young people through science. However, we also witnessed a contradictory belief set centred around the 'teacher as final authority'. This drove many of her teaching decisions. Despite her stated beliefs that children should learn to think independently, some of her observed classroom practices diminished their ability to do so. The data suggests that Vanessa's beliefs about efficiency in the classroom, the need to accomplish particular learning intentions, and her desire to assert her own environmental views related to her beliefs relating to 'teacher as final authority'. The need to enact this sometimes outweighed her belief set for fostering pupils' abilities to problem solve and make their own decisions. This second belief cluster may have militated against Vanessa's efficacy in moving curriculum change forward. This example indicates a tension between these two perspectives which is probably present for all the teachers in different degrees.

\section{Conclusions}

A number of themes emerge from the research: these relate to leadership, teacher autonomy and engagement, sources of impetus and support for innovation, and the importance of co-constructing meaning through dialogue. Our research points to the importance of considering these ingredients, not as isolated factors that can be controlled by the implementation of various strategies on the part of individual teachers, schools or policy makers, but rather as interacting parts. This demands that we consider the process of change in a more complex relational manner than is often the case, analysing how these ingredients come together in their particular enactments in specific settings. Moreover, the research strongly suggests that for change to be sustained, it is necessary to address the wider social, cultural and policy environment within which teachers operate and to look more closely at how these interact with the dynamics of the classroom and school environments in which the curriculum enactments are carried out. Such analysis should include consideration of how particular configurations of relationships in school might serve to help or hinder the process of engaging with new policy. 
In making such analyses, critical realism offers many possibilities. We have focused in this paper on illustrating how Archer's social theory may be used to make sense of data pertaining to the social processes that feed into social change and reproduction. Analytical dualism thus provided us with a methodology for the analysis of social interaction in the various settings that comprised our case studies, with a focus on the factors that influence change and reproduction within the settings in question. The depth ontology and the concept of emergence allowed us to consider how underlying mechanisms and particular configurations of social factors exert causative influence on events and entities. We witnessed how a set of cultural forms (the policies) and associated social structures (the teacher networks) facilitated changes in practice (morphogenesis), while at a different stratum of the system, social structures (school systems) and prevailing cultural forms (school traditions) served to impede change (morphostasis).

However, the analysis of data using this heuristic pointed to a number of limitations in the research. This theoretical approach could have been more explicitly used to show how particular policies lead to particular, new forms of emergence: structural, cultural and individual. However, the focus of our research precluded the development of firm conclusions in this area, as the data did not provide a clear picture of the forms that morphostasis and morphogenesis took in each setting. Nor did they allow us to track such cycles over time. Further, research, with a more explicit longitudinal focus would be required to map structural, cultural and individual emergence in such a fashion. Such research would need to develop more precise instruments for recording cultural, structural and individual dimensions of morphogenetic and morphostatic cycles This is especially the case for gaining access to teachers' thinking, including tracking inner dialogue (Archer 2000) as it occurs, and in mapping the relational/structural aspects of each context so that strong inferences may be made about the existence of underlying social mechanisms. Our conclusion at this stage, drawn from undertaking our analysis, is that Archer's social theory promises much in terms of providing a methodology for understanding social processes in educational innovation; but there is considerable substantive work yet to be done in realising this 
promise. It presently offers the tool making tools (Balkin 1998), if not yet the specific methodological tools themselves for tackling this task.

\section{References}

Archer, M. (1988). Culture and Agency: the place of culture in social theory. Cambridge: Cambridge University Press.

Archer, M. (1995). Realist Social Theory: the morphogenetic approach. Cambridge: Cambridge University Press.

Archer, M. (2000). Being Human: the problem of agency. Cambridge: Cambridge University Press.

Balkin, J.M. (1998). Cultural Software: A Theory of Ideology. London: Yale University Press.

Cuban, L. (1998). How schools change reforms: redefining reform success and failure. Teachers College Record, 99, no. 3: 453-477.

Doyle, W. and Ponder, G.A. (1977). The Practicality Ethic in Teacher Decision-Making, Interchange, 8, no.3: 1-12.

Elder-Vass, D. (2007). Emergence and the realist account of cause. Journal of Critical Realism, 4, no. 2: 315-38.

Elder-Vass, D. (2008a). Searching for realism, structure and agency in Actor Network Theory. British Journal of Sociology, 59, no. 3: 455-473.

Elder-Vass, D. (2008b). Integrating institutional, relational, and embodied structure: An emergentist perspective. British Journal of Sociology, 59, no. 2: 281-99.

Elmore, R.F. (2004). School Reform from the Inside Out: policy, practice, performance. Cambridge, MA.: Harvard Education Press.

Giddens, A. (1984). The Constitution of Society: outline of the theory of structuration. Cambridge: Polity.

Hayward, L. and Boyd, B. (2009). Building Teacher Learning Communities. Dingwall, The Highland Council.

Hayward, L., Priestley, M. and Young, M. (2004). Ruffling the Calm of the Ocean Floor: Merging Practice, Policy and Research in Assessment in Scotland. Oxford Review of Education, 30, no. 3: 397-416. 
Hayward, L. and Spencer, E. (2010) The complexities of change: formative assessment in Scotland, The Curriculum Journal, 21, no. 2: 161-177.

Hutchinson, C. and Hayward, L. (2005). The journey so far: assessment for learning in Scotland, The Curriculum Journal, 16, no. 2: 225-248.

LTScotland (2009). Future Learning and teaching Programme. Available online at: http://staging.Itscotland.org.uk/lts/flat/aboutflat.asp (accessed 7 October 2009).

Miller, K., Edwards, R., and Priestley, M. (2010). Levels and equivalence in credit and qualifications frameworks: Contrasting the prescribed and enacted curriculum in school and college. Research Papers in Education, 25, no. 2: 225-243.

Osborn, M., Croll, P., Broadfoot, P., Pollard, A., McNess, E. and Triggs, P. (1997). Policy into practice and practice into policy: creative mediation in the primary classroom. In G. Helsby and G. McCulloch (Eds) Teachers and the National Curriculum. London, Cassell.

Porpora, D. V. (1998). Four concepts of social structure. In M. Archer, R. Bhaskar, A. Collier, T. Lawson, and A. Norrie (Eds.) Critical Realism: essential readings. London: Routledge.

Priestley, M. and Humes, W. (2010). The development of Scotland's Curriculum for Excellence: amnesia and déjà vu. Oxford Review of Education, 36, no. 3: 345-361.

Priestley, M., Miller, K., Barrett, L. and Wallace, C. (2011). Teacher learning communities and educational change in Scotland: the Highland experience. British Educational Research Journal, 37, no. 2: 265-284.

Reeves, J. (2008). Between a rock and a hard place? A Curriculum for Excellence and the Quality Initiative in Scottish schools. Scottish Educational Review, 40, no. 2: 6-16.

Sarason, S. B. (1990). The Predictable Failure of Education Reform. Oxford: Lesley-Bass Publishers.

Scott, D. (2000). Realism and Educational Research: new perspectives and possibilities. London: RoutledgeFalmer.

Scott, D. (2010) Education, Epistemology and Critical Realism. London: Routledge. 
Scottish Government (2008). Building the Curriculum 3: a framework for learning and teaching. Edinburgh, Scottish Government.

Supovitz, J.A. (2008). Implementation as Iterative Refraction. In J.A. Supovitz and E.H. Weinbaum (Eds), The Implementation gap: understanding reform in high schools. New York, Teachers College Press.

Supovitz, J.A. and Weinbaum, E.H. (2008). Reform Implementation Revisited. In J.A. Supovitz and E.H. Weinbaum (Eds), The Implementation gap: understanding reform in high schools. New York, Teachers College Press.

Wallace, C. and Priestley, M. (in press) Teacher beliefs and the mediation of curriculum innovation in Scotland: A socio-cultural perspective on professional development and change, Journal of Curriculum Studies.

Wheelahan, L. (2010). Why knowledge matters in curriculum: a social realist argument. London: Routledge.

\footnotetext{
${ }^{1}$ The FLaT initiative made available government funding to local authorities and schools to support pedagogic innovation, which would 'enrich young people's learning experiences; promote attainment and achievement; tackle barriers to inclusion; create a learning and teaching environment that is sensitive to individual needs' (LTScotland 2009).

${ }^{2}$ While we social interaction here, one should not forget that human transactions occur with the material world too. Indeed, Archer (2000) posits a complex web of relationships with what she terms the social, practical and natural worlds. However, although for the sake of simplicity we confine the discussion here to social relations, whilst acknowledging the importance of material transactions in social transformation and reproduction.

${ }^{3}$ Chartered Teacher status is a Scottish initiative to enhance the teaching practice of experienced teachers. It is linked to a post-graduate qualification, which may be extended to Master's level. There is a strong focus in such study on professional practice through the medium of professional enquiry/action research.
} 